\title{
Papers
}

\section{Why men with prostate cancer want wider access to prostate specific antigen testing: qualitative study}

\author{
Alison Chapple, Sue Ziebland, Sasha Shepperd, Rachel Miller, Andrew Herxheimer, \\ Ann McPherson
}

\begin{abstract}
Objectives To explore the attitudes of men with confirmed or suspected prostate cancer to testing for prostate specific antigen.

Design Qualitative interview study with a purposive sample.

Setting Great Britain.

Participants 52 men with suspected or confirmed prostate cancer, recruited through general practitioners, urologists, patient support groups, and charities.

Results Almost all men remembered their prostate specific antigen test but recalled being given little information beforehand. Arguments in favour of increased access to testing included the belief that early diagnosis would reduce mortality, improve quality of life, and save the NHS money. Men also thought that a national screening programme should be available because symptoms can be ambiguous, screening for cancer is responsible health behaviour, and screening would encourage men to be tested. Four men who opposed a screening programme had gathered information alerting them to uncertainty about the benefits of treatment, and two regretted that they had been tested. Others thought that access to testing is restricted in the United Kingdom because of a lack of government backing, concerns about the accuracy of the test, and a lack of resources.

Conclusions The few men in this study who subscribed to the argument that evidence of the benefits of treatment is a prerequisite for a screening programme did not want to see screening introduced. Men who proposed an alternative set of principles for testing gave reasons that did not all relate to overoptimism about the benefits of early diagnosis. People who plan services and people who respond to requests for testing need to understand men's perspectives and concerns.
\end{abstract}

\section{Introduction}

A screening programme is justified if the screening test is accurate and effective treatment is available. Screening for prostate cancer cannot be justified while uncertainty remains about whether early detection and treatment of saves lives. ${ }^{1-3}$ However, support groups for men with prostate cancer and much of the media do not question the benefit of screening and rarely mention the lack of evidence supporting open access to testing for prostate specific antigen. ${ }^{45}$

Participation by women in the existing national screening programmes for breast cancer and cervical cancer has been presented as responsible health behaviour, ${ }^{6}$ and its benefits are thought to include detecting disease at an earlier and more treatable stage. In several countries men are similarly encouraged to have a prostate specific antigen test on the grounds that screening for prostate cancer represents good preventive health care, ${ }^{7-9}$ particularly in the context of an increasing incidence of prostate cancer. These arguments are especially powerful when expressed by men with prostate cancer and, combined with the attention from the media on screening for prostate cancer, explain why pressure for such screening has gained widespread popular support. ${ }^{18}{ }^{10}$ Men may find it contradictory that they are being encouraged to pay more attention to their health yet a prostate specific antigen screening programme has not been established in the United Kingdom. ${ }^{11}$

Concern has been expressed that men receive little or no information before having a prostate specific antigen test. ${ }^{7}$ Although men who have received reliable information on screening are less inclined to request the test, many men continue to request it. ${ }^{12}$ Men with prostate cancer clearly do not represent all men who might seek a prostate specific antigen test, but as "cancer survivors" their views command attention and have influence through the media. Their perspective is therefore important in helping to define what information men need when considering a prostate specific antigen test.

\begin{tabular}{l} 
Editorial by \\
Thornton \\
Papers $\mathrm{p} 737$ \\
Education and debate \\
$\mathrm{p} 766$ \\
\hline
\end{tabular}

DIPEx, Department of Primary Health Care, University of Oxford, Institute of Health Sciences, Oxford OX3 7LF

Alison Chapple senior research fellow Sasha Shepperd university research lecturer

Rachel Miller honorary research fellow

Andrew

Herxheimer emeritus fellow, UK Cochrane Centre Ann McPherson research lecturer

Cancer Research UK General Practice Research Group, Department of Primary Health Care, University of Oxford

Sue Ziebland senior research fellow Correspondence to: A Chapple alison.chapple@ dphpc.ox.ac.uk

bmj.com 2002;325:737

\section{Method}

\section{Sample}

Having obtained ethics committee approval, we invited men with suspected or confirmed prostate cancer to be interviewed for DIPEx (database of individual patients' experience of illness). ${ }^{13}$ With their informed consent, we interviewed 52 men from throughout Great Britain. Men described many aspects of their experience of illness, but here we report only what they said about prostate specific antigen testing. Purposive sampling ensured a wide range of experiences and views. ${ }^{14} \mathrm{We}$ 
included men who had prostate specific antigen tests because of their symptoms, men who received a diagnosis after routine private health checks, and participants in UK trials that included prostate specific antigen testing. Interviewing continued until the sample included men at different stages of diagnosis with experience of a wide range of treatments and until no new themes emerged from the data. We recruited men through general practitioners, urologists, patient support groups, and charities. The table shows the characteristics of the sample.

\section{Interviews}

All but three men were interviewed in their homes, between September 2000 and January 2001. One of the authors (AC), a medical sociologist, conducted almost all the interviews. The interviewer asked the men to tell their story, from when they first noticed their symptoms or had a prostate specific antigen test, with prompts about specific issues. Almost all the men discussed the prostate specific antigen test, because most were asked about the information they had received before having it. As interviewing progressed it became apparent that some men were concerned about the lack of routine testing for prostate specific antigen, and later interviews explored this issue. Almost half the men specifically discussed this subject. All interviews were audiotaped and lasted one to three hours.

Characteristics of 52 men interviewed about prostate cancer

\begin{tabular}{lc} 
Characteristic & No of men \\
\hline Age (years): & \\
\hline $50-60$ & 10 \\
\hline $61-70$ & 21 \\
\hline $71-85$ & 21 \\
\hline Ethnicity: & 48 \\
\hline White British & 1 \\
\hline Black Caribbean & 1 \\
\hline Black Nigerian & 1 \\
\hline Indian & 1 \\
\hline From former Czechoslovakia & \\
\hline Employment (includes retired): & 24 \\
\hline Professional or higher managerial & 19 \\
\hline Other non-manual & 8 \\
\hline Skilled manual & 1 \\
\hline Unskilled manual & \\
\hline Circumstances that led to diagnosis: & 41 \\
\hline Had symptoms before having a PSA test & 11 \\
\hline Had a PSA test as part of routine health check \\
\hline Type of treatment* (some have had more than one treatment): \\
\hline No treatment because cancer not confirmed \\
\hline Watchful waiting (one man had TUR in 1982) \\
\hline TUR (followed by one or more of the treatments listed below) \\
\hline Hormone treatment & 2 \\
\hline External beam radiation & 17 \\
\hline Radical prostatectomy & 32 \\
\hline Brachytherapy & 20 \\
\hline Orchidectomy & 3 \\
\hline Cryosurgery & 3 \\
\hline Vaccine trial or antigen therapy & 3 \\
\hline Chemotherapy & 2 \\
\hline & \\
\hline
\end{tabular}

PSA=prostate specific antigen; TUR=transurethral resection. *Figures include men who had hormone treatment for a short time before radiotherapy or surgery and men who had external beam radiation for bone pain.

tRadioactive seeds or rods are inserted into the prostate to destroy the cancer over a period of time.

\section{Analysis}

Respondents reviewed full transcripts. Subsequent data analysis involved examining sections of the interviews thematically across the whole dataset as well as in the context of each man's interview. ${ }^{15}$ We expected to find that prostate specific antigen tests were undertaken without much previous information, but the other themes discussed below emerged during data collection. ${ }^{16}$ Inter-rater reliability scores were not developed, as interviews were relatively unstructured, ${ }^{17}$ but two authors (AC, SZ) regularly discussed coding and results.

\section{Results}

The results of the thematic analysis are described under broad headings and illustrated with extracts from the most apposite interviews.

\section{Lack of information about the implications of the test}

More than three quarters of the men we interviewed had consulted their general practitioner because of urinary symptoms, and almost all remembered having had a prostate specific antigen test. Men without urinary symptoms who had had tests included four who were temporarily living overseas and two who were offered tests as part of a trial. Others had been tested as part of company or private health checks or during investigations for seemingly unrelated problems.

Men who had had tests during investigation of urinary symptoms might be expected to have a different experience and perspective from those who were offered a routine test. However, whether or not they had presented with symptoms, men recalled being given little information at the time of the test. Although some men remembered being told that the test was not accurate, the implications of the test were usually discussed only after the result had been found to be abnormal (box 1).

Men diagnosed with prostate cancer may be relieved that the cancer has been identified and treated and may be disinclined to question how much information they were given. However, men without pretest symptoms may be more likely to question the level of information they received. For example, one man (P26) believed himself to be healthy before he had the test. His prostatectomy caused impotence, urinary symptoms, and other problems. Although he concluded that he was glad he had had the test, he felt that he should have been given more information, and at one point in the interview he seemed ambivalent about the consequences of his test:

"I now (wonder) what if I hadn't had a PSA test, what if I didn't know about the PSA? My quality of life, I've no doubt, would have been much greater than what I've experienced in the past six years. But having not had the benefit of a PSA test, how do I know then what my current situation would have been? Would it have been 'Sorry, too late' and ... I've heard so many fellow patients saying 'God, I wish I'd had an early PSA.' On the other hand, I've missed my quality of life, but would I have missed my life now if I hadn't had a PSA?" (P26, PSA test as part of trial offered by his general practitioner) 
Box 1: Lack of information about implications of prostate specific antigen result

\section{Interviewer's question}

How much information were you given about the PSA test and the implications of any results you might have?

\section{Responses}

"Almost nil, it was just an invitation because of my age. Because the [general practitioner] surgery had been invited to take part in the screening the information given to me was well you should because of your age, and even though I said well I didn't know I was suffering with any symptoms, well I was still persuaded to carry out the screening process because of it being beneficial." (P26, invited to participate in trial)

"I wasn't told anything about it initially [at the general practitioner's surgery]. I didn't even know what the PSA was or what the implications of a high score were, or what was a high score. I was just told that a PSA blood test was going to be done and that was that." (P31, presented with symptoms)

"Well, it's called a PSA, but I didn't know that at the time [at the hospital]. It was just a blood test, and I really was treating it fairly nonchalantly ... When I went back [to the general practitioner] and he opened the conversation by saying "There's every chance you've got prostate cancer,' I was quite shattered." (P08, presented with symptoms)

"I immediately responded that I'd never heard of PSA and what did it stand for and what was it for? And I don't think I really took in what he was saying, but I agreed to take the PSA test primarily to humour him rather than because I'd really considered all the risks and benefits of taking the test." (P03, routine test in US, cancer not confirmed)

"Before I had my PSA test I wasn't given that much information. I just went along and they took several blood samples ... I wasn't really worried about the PSA to be honest because I had no problems with my water works. I went along very confident." (P01, invited to participate in trial)

\section{Reasons for recommending testing}

All but four men (discussed later) who discussed routine PSA testing were keen to see others, including their own friends and sons, have a prostate specific antigen test. Their reasons included the following (boxes 2 and 3).

Beliefs about the benefits of early diagnosis-Many men believed that early diagnosis is important for cure of cancer or to prevent it spreading. Because prostate cancer can be present without symptoms, men reasoned that only a routine national screening programme would suffice. One man noted that when the change in the prostate specific antigen concentration is important for diagnosis, regular repeat tests are needed.

Responsibility-Men regarded participation in screening as responsible behaviour, and several made comparisons with women's cancer screening programmes. Two men suggested that early diagnosis through prostate specific antigen testing would save the NHS money.

Avoiding regrets-For some men the "avoidance of regrets" was important. The man (P26) quoted above, who questioned the effect that treatment had had on his life, knew of others who regretted not having an earlier test and so advised other men to go for early diagnosis. Newspaper articles and popular medical books with patients' stories also highlight this issue. ${ }^{518}$

$A$ right to information and improved access-Some men asserted that it should be a right to have a prostate specific antigen test and that if the government is not going to introduce screening then men should seek the test. Others suggested that because men are reluctant users of health services they needed a screening programme to encourage them to have the test without embarrassment.

Equitability-Many men discussed rights and parity with other healthcare spending, particularly screening programmes for women. It was also suggested that if prostate cancer had a higher profile more would be spent on research and treatment, thus leading to improved detection and cure.

\section{Views about why prostate specific antigen screening is not yet available}

Some of the men who favoured screening thought a programme had not been implemented in the United Kingdom because the government had taken bad advice, was reluctant to fund screening, and lacked resources to treat the men who would be identified

Box 2: Reasons for recommending a prostate specific antigen screening programme: a better chance of being cured and a right to information

"If you are over 50 you should have a PSA test every year to make sure you don't have this problem, and if you do the quicker you get onto it the better your chances of being cured." (P36, routine PSA check, support group member)

"The five year survival rate in this country is about $42 \%$; in America it's between $85 \%$ and $90 \%$, and this is very largely due to far more people being scanned for prostate cancer by PSA and DRE [digital rectal examination] and it being caught at an early stage when it is still treatable." (P34, support group member who had searched the internet)

"In America the mortality rate has come down quite significantly because more PSA tests are carried out there than in this country, but we feel that that's because in America you pay your doctor for a consultation." (P32, support group member who had searched the internet)

I believe that in the States, many of the American states, PSA is obligatory or on offer for everyone over $50 \ldots$. In view of the fact that it [cancer] is relatively easy to get rid of if it's caught in time, a PSA test ought to be a requisite for every man over 50 . And I'm delighted that many of my friends have gone off and had the PSA test." (P07, who had searched the internet)

"We require more money to be spent on prostate cancer, and the earlier it is diagnosed the better, and I feel that if it was diagnosed earlier this would also save the health service money, which is in short supply." (P35, support group member)

"I would say have regular PSA tests. I think men have a right to know even if it's difficult to interpret the results, and I think you should know, and if the government is not going to do it for you, which they're probably not, then you should do it for yourself." (P27) 
with prostate cancer. Concerns about the accuracy of the test were mentioned but not considered a convincing deterrent: "I believe that the PSA test, for all its weaknesses, and I understand those, men should have [them]. It's outrageous to suggest to men that they shouldn't have one ... I think the government is completely wrong, and I'm afraid to say that a lot of it is to do with trying to save resources." (P27)

\section{Men who are not in favour of a screening programme}

Four men said that they were against national screening for prostate cancer; two had had a prostate specific antigen test as part of a health check, and the other two had been tested after seeing their doctor with symptoms. The interviewer explored the perspectives of these men and sought explanations for their atypical responses. ${ }^{19}$

One man who had seen an American educational video about prostate specific antigen testing, which demonstrates uncertainty about the treatment options for men with prostate cancer, concluded that "To go to total screening would terrify so many people that you would cause a lot more harm than good ... It shouldn't be done until you've got a guaranteed test and an assured treatment." (P33, tested during investigation of symptoms, had prostatectomy)

Another man, who had been influenced by a doctor in his family, thought that only men at high risk should be tested: "I think to screen the whole of the male population, and then simply say to them 'Well, actually we are not quite sure what to do about it,' is probably not terribly helpful to people, and for a lot of people might be quite destabilising." (P49, tested during investigation of symptoms, watchful waiting)

Box 3: Reasons for recommending a PSA screening programme: equitability and the belief that screening would save the NHS money

"Women get screening tests for breast cancer, which has helped an awful lot of people, and I think men, when they get to 50, they should get these PSA tests as a national thing ... so that they can catch things early and stop the cancer spreading to the bones." (P37, support group member)

"I believe that PSA screening after a certain age, say 50 or 55 , should be exactly the same as breast cancer screening, because I believe in the long run it will save the NHS money, and I believe it would save lives." (P41)

"But I would think anybody who were in their 50 s now and have some sort of problem with their waterworks should ask if they can have a prostate test. But until they put more funds into research into prostate cancer and government backing on people being tested over 50 years of age, it is going to be a slow process." (P01)

"I really believe PSA testing and screening should be done. There's so many cases where they jump up and down and say 'Why worry someone to death when we don't have an effective treatment for it?' Well why don't we have an effective treatment for it? Basically because we haven't spent the money on getting it; it's out there and available in America ... But the criminal thing, in 1999, the actual funds for breast screening were $£ 3.8$ million and the funds for prostate were $£ 47$ 000.” (P46)
The remaining two men had been found to have raised prostate specific antigen readings when routinely tested, and both regretted having had the test. One, who was 74 years old, had had a routine prenuptial test in the United States. He decided, after asking medical friends and getting a second opinion, that treatment was too invasive and decided on watchful waiting: "I had read up on things, and I was terrified of either incontinence or lack of sex. . . Basically I wish I hadn't known. I would have happily lived on in ignorance." (P22)

The other man was 61 years old and had had a routine test when living in the United States. Although his prostate specific antigen concentration was raised, cancer was not diagnosed. He became intensely anxious and expected to die. After searching the internet he concluded that surgery was akin to "butchery" and said he would prefer a shorter good quality life to living with probable incontinence and impotence: "I wish I had never had the very first PSA test ... I think my principal point is really that it requires very informed consent in the same way that patients have to give informed consent to an HIV test. People should be taken through the worst case scenarios and see how they would cope with that." (P03, routine test, no cancer confirmed).

Notably, whereas men who recommended screening compared the prostate specific antigen test to screening for breast and cervical cancer in women, the two men who regretted their routine tests emphasised that men seeking a prostate specific antigen test should have pretest counselling, as used for HIV testing.

\section{Discussion}

This study looks at testing for prostate specific antigen from the unique viewpoint of men with suspected or confirmed prostate cancer. We present the data as themes, and not as relative frequencies, because qualitative studies cannot represent the wider population numerically. ${ }^{20}$ The sample was selected to represent the widest practical range of experiences of men with prostate cancer. Over half of our volunteers were well educated white men; interviews with more manual workers and more men from other ethnic groups might have identified additional issues.

Although we did identify misunderstandings, including optimism about the benefits of early diagnosis, men with prostate cancer who advocate screening are not simply uninformed. We suggest that many of these men are following a different set of principles from those intended to guide screening programmes, ${ }^{21}$ and men who advocated screening did not dwell on the lack of a clear treatment choice. The four men who opposed screening knew that there was no treatment proved to be effective, and crucially they accepted that this was a deterrent to screening. Epidemiological data indicate that screening for prostate cancer has serious disadvantages, including inaccurate testing, lack of evidence that treatment reduces mortality, and serious adverse effects of treatment. ${ }^{22}$

It is no surprise that men believe that prostate specific antigen testing offers health benefits. Several men, particularly members of support groups and users of the internet, cited the "positive" effects of screening programmes in the United States and Austria. 


\section{What is already known on this topic}

The media report enthusiasm for both testing and screening for prostate specific antigen among men with prostate cancer

Relatively little is known about men's experiences of such testing

\section{What this study adds}

The study helps to explain why most men with prostate cancer strongly advocate prostate specific antigen testing and screening

It also shows that many men are ill prepared for test results and for the possible iatrogenic effects of treatment

However, they may not have been aware of the serious limitations of these data, such as the problem of lead time bias. ${ }^{23}$ Many men with prostate cancer suspect that official reluctance to encourage a national programme is prompted by cost concerns and a misunderstanding of the evidence. The fact that prostate specific antigen testing is offered routinely to men with private health insurance in the United Kingdom may promote the notion that it is valuable.

General practitioners in the United Kingdom have been advised to ensure that men who have a prostate specific antigen test are making an informed choice. ${ }^{24}$ A key component of this information should be the uncertainty about the benefits and risks of treatment. However, arguments based on principles such as the "right to information" about one's health, equality, and the "imperative to avoid regret" will persuade some men to have the test, even if they understand that no treatment is known to prolong life. An additional argument for screening, which may persuade even those who know that the research evidence is inadequate, is that a screening programme would raise the profile of the condition and thus enhance the probability of developing effective treatments. Policy makers and politicians, as well as doctors, need to understand why people want wider access to prostate specific antigen testing, so that they can find better ways of communicating information about risk.
We thank the men who took part in the interviews, the people who helped to recruit volunteers, and Jane Melia for usefu comments on an earlier draft of this paper. Pamela Baker and Janet Caldwell gave invaluable help with administrative matters. Contributors: AC interviewed most of the men for this study and analysed the data in collaboration with $\mathrm{SZ}$. $\mathrm{AMcP}$ and $\mathrm{AH}$ had the original idea for the wider DIPEx project, and SZ, RM, and SS have been involved in the project since it began. AC drafted the paper; all the authors contributed to the subsequent drafts and final version. AC and $\mathrm{SZ}$ will act as guarantors for the work.

Funding: National Screening Committee.

Competing interests: None declared.

1 Barry M. Prostate specific antigen testing for early diagnosis of prostate cancer. N Engl J Med 2001;344:1373-7.

Neal D, Donovan J. Prostate cancer: to screen or not to screen? Lancet Oncol 2000;1:17-24.

3 Tannock I. Eradication of a disease: how we cured asymptomatic prostate cancer. Lancet Oncol 2000;May:17-9.

What fails men? PSA Newsletter 2000;4:2

5 Lee-Potter L. How my wife saved my life. Daily Mail July 8 2000:4

6 Howson A. Cervical screening: compliance and moral obligation. Sociology of Health and Illness 1999;21:401-25.

7 Slevin T, Donnelly N, Clarkson J, English D, Ward J. Prostate cancer testing: behaviour, motivation and attitudes among Western Australian men. Med J Aust 1997;171:185-8.

8 Ward J, Hughes A, Hirst G, Winchester L. Men's estimates of prostate cancer risk and self-reported rates of screening. Med J Aus 1997; 167:250-3

9 Taylor K, DiPlacido J, Redd W, Faccenda K, Greer L, Perlmutter A. Demographics, family histories, and psychological characteristics of prostate carcinoma screening participants. Cancer 1999:85:1305-12.

10 Stuttaford T. Wake up call for the prostate. Times September 14 2000:10.

11 Donovan J, Frankel S, Neal D, Hamdy F. Screening for prostate cancer in the UK. BMJ 2001;323:763-4

12 Volk R. Spann S. Decision-aids for prostate cancer screening. J Fam Pract 2000;49:425-7.

13 Herxheimer A, McPherson A, Miller R, Shepperd S, Yaphe J, Ziebland S. Database of patients' experiences (DIPEx): a multi-media approach to sharing experiences and information. Lancet 2000; 355:1540-3. [See also www.dipex.org for an update about this project.]

14 Coyne I. Sampling in qualitative research. Purposeful and theoretical sampling; merging or clear boundaries? J Adv Nurs 1997;26:623-30

15 Malterud K. Qualitative research: standards, challenges, and guidelines Lancet 2001;358:483-8.

16 Pope C, Ziebland S, Mays N. Analysing qualitative data. BMJ 2000;320:114-6.

17 Morse JM. "Perfectly healthy but dead": the myth of inter-rater reliability. Qual Health Res 1997;7:445-7.

18 Stuttaford T. A test that could save thousands of men. Times June 8 2000:21.

19 Silverman D. Interpreting qualitative data. London: Sage, 1994

20 Malterud K. The art and science of clinical knowledge: evidence beyond measures and numbers. Lancet 2001;358:397-400.

21 UK National Screening Committee. Second report of the UK National Screening Committee. London: Department of Health, 2000.

22 Brawley O. Prostate carcinoma incidence and patient mortality: the effects of screening and early detection. Cancer 1997;80:1857-63.

23 Grimes D, Schulz K. Uses and abuses of screening tests. Lancet 2002 359:881-4.

24 Department of Health press release 2001/0302. Launch of informed choice project for prostate cancer, 4 July 2002 (http://tap.ccta.gov.uk/ doh/intpress.nsf/page/2001-0302)

(Accepted 4 April 2002) 